\title{
Evaluasi Tata Ruang Wilayah Distrik Mayamuk Dengan Menggunakan Aplikasi ArcGIS
}

\author{
RahmanWinarto ${ }^{1}$, HendrikPristianto ${ }^{2}$, Ibrahim ${ }^{3}$ \\ ${ }^{1}$ Mahasiswa Program Studi Teknik Sipil Universitas Muhammadiyah Sorong \\ ${ }^{2,3}$ Dosen Program Studi Teknik Sipil Universitas Muhammadiyah Sorong
}

\begin{abstract}
Abstrak
Kegiatan evaluasi tata ruang wilayah Distrik Mayamuk pada prinsipnya untuk menilai keselarasan antara tujuan, strategi, dan kebijakan yang termuat dalam dokumen rencana tata ruang wilayah (RTRW) Kabupaten Sorong. Tujuan penelitian in iadalah untuk 1)Mengetahui perbandingan luas menurut RTRW dengan hasil analisis, 2)Mengetahui kesesuaian rencana tata ruang pada dokumen rencana tata ruang wilayah (RTRW) Kabupaten Sorong Distrik Mayamuk dengan yang terlaksana di Distrik Mayamuk, 3)Menghasilkan produk peta pola ruang tiap kelurahan dan peta tata ruang serta peta administrasi Distrik Mayamuk tahun 2017. Metode penelitian adalah pengambilan data citra foto udara dengan drone atau pesawat tanpa awak, data yang dikumpulkan adalah data primer dari citra foto udara dan data sekunder dari dokumen RTRW dan BPS Kab. Sorong. Kesimpulan yang dihasilkan adalah 1)Hasil penelitian menunjukkan bahwa perbandingan luas Distrik Mayamuk adalah selisih 83,76 Ha. 2)Hasil analisis pola ruang Distrik Mayamuk kawasan lindung cagar alam sebesar 1,92 \%, kawasan budidaya hutan produksi (HPK) sebesar 92,16\%, permukiman sebesar 1,42\%, pertanian lahan kering (PLK) sebesar 4,29\%, kawasan industri dan pelabuhan terpadu sebesar 0,16\% dan lahan kosong sebesar 0,02\%, 3)Hasil peta pola ruang Kelurahan Makotyamsa, Makbalim, Yeflio, Makbusun, Arar, Klain, Klasmelek, Wen dan peta tata ruang serta peta administrasi Distrik Mayamuk.
\end{abstract}

Kata Kunci : Arcgis, Evaluasi, Pola Ruang, Tata Ruang,

\section{Pendahuluan}

\section{Latar belakang}

Distrik Mayamuk adalah sebuahdistrik di kabupaten Sorong, Papua Barat, Indonesia. Distrik Mayamuk yang baru-baru ini mengalami pemekaran kelurahan menjadi 8 kelurahan diantaranya sebagai berikut: Kelurahan Makotyamsa, Kelurahan Makbalim, Kelurahan Yeflio, Kelurahan Makbusun, Kelurahan Arar, Kelurahan Klain, Kelurahan Klasmelek, dan Kelurahan Wen. Dari pengamat lingkungan menilai belum adanya kesesuaian rencana tata ruang wilayah sehingga dilakukan evaluasi. Evalusi merupakan kegiatan untuk menilai kesesuaian antara tujuan dan hasil dari suatu kegiatan yang didasarkan pada suatu pedoman khusus.

Kegiatan evaluasi tata ruang wilayah Distrik Mayamuk pada prinsipnya untuk menilai keselarasan antara tujuan, strategi, dan kebijakan yang termuat dalam dokumen rencana tata ruang wilayah (RTRW) Kabupaten Sorong.

\section{Tujuan Penelitian}

Tujuan dari penelitian ini adalah untuk :

1) Mengetahui perbandingan luas menurut RTRW dengan hasil analisa

2) Mengetahui kesesuaian rencana tata ruang pada dokumen rencana tata ruang wilayah (RTRW)
Kabupaten Sorong Distrik Mayamuk dengan yang terlaksana di Distrik Mayamuk.

3) Menghasilkan produk peta pola ruang tiap kelurahan dan peta tata ruang serta peta administrasi Distrik Mayamuk tahun 2017.

\section{Batasan Masalah}

Dengan mempertimbangkan luasnya permasalahan yang timbul serta keterbatasan waktu dan kemampuan, maka perlu adanya batasan masalah agar memperjelas dalam menganalisa permasalahan sebagai berikut:

1) Penelitian ini dilakukan di wilayah Distrik Mayamuk

2) Dokumen Rencana Tata Ruang Wilayah (RTRW) Kabupaten Sorong 2012 - 2032

\section{Metodologi penelitian Lokasi Penelitian}

\footnotetext{
* Corresponding author. Telp.:0812-4747-8013

E-mail addresses: rahman.winarto96@gmail.com
} 


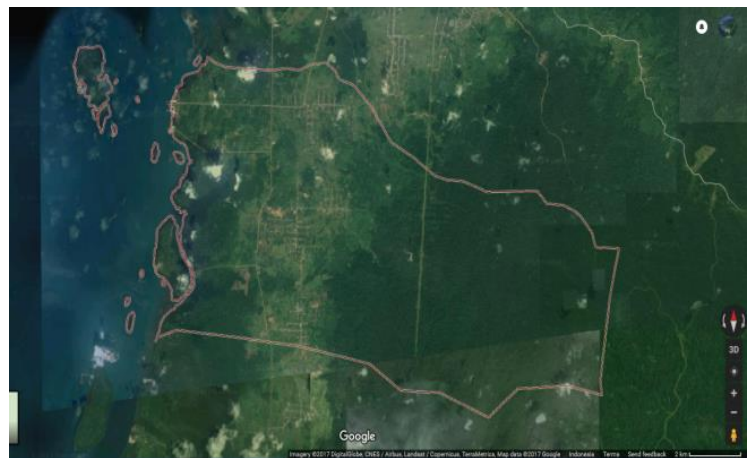

Gambar 1. Lokasi Pengambilan dan Tempat Penelitian

\section{Tahapan Penelitian}

Pada penelitian ini penulis menggunakan metode seperti berikut :

1) Mengumpulkan data sekunder dari dokumen rencana tata ruang wilayah (RTRW) Kabupaten Sorong.

2) Mengumpulkan data primer dilapangan meliputi, foto dokumentasi dan pengambilan foto citra udara menggunakan drone.

3) Melakukan proses penggabungan foto dengan software Agisoft photoscane.

4) Setelah foto citra udara tergabung, maka dapat dilanjutkan pengolahan pembuatan peta dangan software Arc maps/gis.

5) Hasil produk peta dan menyimpulkan hasil penelitian evaluasi tata ruang Distrik Mayamuk.

\section{Peralatan Yang digunakan}

Beberapa peralatan yang dipakai untuk menunjang penelitian ini adalah sebagai berikut :

A. Perangkat Keras (Hardware)

1) Ultrabook dan Notebook untuk mengolah foto citra udara menjadi peta.

2) Drone Dji Phantom 4 untuk mengambil foto citra udara.

B. Perangkat Lunak (Software)

1) Sistem operasi win 10 .

2) Agisoft photocane untuk mengabungkan fotofoto citra udara.

3) Photoshop CS3 untuk mengabungkan foto-foto yang tidak dapat digabungkan pada agisoft photocane

4) Arc Maps versi 10.3 untuk membuat peta

\section{Hasil dan Pembahasan}

\section{Perbandingan luas Distrik Mayamuk menurut RTRW dengan hasil analisis}

Setelah melakukan pengambilan data di lokasi penelitian terutama dengan menggunakan drone dan diolah menjadi peta maka didapat perbandingan luas distrik RTRW dengan hasil analisis sebagai berikut:

Tabel 1. Perbandingan luas Distrik Mayamuk

\begin{tabular}{|c|c|c|c|c|}
\hline $\mathrm{o}^{\mathrm{N}}$ & $\begin{array}{l}\text { Dat } \\
\text { a }\end{array}$ & Distrik & $\begin{array}{c}\text { Luas } \\
\text { Darat }(\mathrm{Ha})\end{array}$ & $\begin{array}{c}\text { Sel } \\
\text { isih } \\
(\mathrm{Ha})\end{array}$ \\
\hline 1 & $\begin{array}{l}\text { RT } \\
\text { RW }\end{array}$ & $\begin{array}{l}\text { Mayam } \\
\text { uk }\end{array}$ & $\begin{array}{c}14.534, \\
47\end{array}$ & 83 , \\
\hline 2 & $\begin{array}{l}\text { Ana } \\
\text { lisa }\end{array}$ & $\begin{array}{l}\text { Mayam } \\
\text { uk }\end{array}$ & $\begin{array}{l}14.450, \\
71\end{array}$ & 76 \\
\hline
\end{tabular}

2. Kesesuaian penggunaan lahan menurut RTRW dengan hasil analisa

Hasil kesesuaian penggunaan lahan sebagai berikut:

1) Untuk kawasan lindung cagar alam yang direncanakan sebesar 4,26\% sedangkan hasil analisis $1,95 \%$ dari luas distrik dengan selisih $2,32 \%$

2) Untuk kawasan budidaya hutan produksi komersial (HPK) yang direncanakan sebesar $2,34 \%$ sedangkan hasil analisis $92,16 \%$ dari luas distrik dengan selisih $89,82 \%$.

3) Untuk kawasan budidaya permukiman yang direncanakan sebesar $12,01 \%$ sedangkan hasil analisis $1,42 \%$ dari luas distrik dengan selisih $10,59 \%$.

4) Untuk kawasan budidaya pertanian lahan kering yang direncanakan sebesar 46,94\% sedangkan hasil analisis 4,29\% dari luas distrik dengan selisih $42,65 \%$.

5) Untuk kawasan lahan kosong dari hasil analisis didapat sebesar $0,02 \%$ dari luas wilayah distrik yang belum dimanfaatkan sesuai peruntukannya.

6) Untuk kawasan budidaya AL yang direncanakan sebesar 4,06\% sedangkan dari hasil analisis belum terlaksana.

\section{Hasil produk peta}

Dari hasil pengolah dari penggabungan foto citra udara dan pembuatan peta dengan aplikasi arcgis dihasilkan peta sebagai berikut :

1) Peta Pola Ruang Kel. Makotyamsa

2) Peta Pola Ruang Kel. Makbalim

3) Peta Pola Ruang Kel. Yeflio

4) Peta Pola Ruang Kel. Makbusun 
5) Peta Pola Ruang Kel. Arar

6) Peta Pola Ruang Kel. Klain

7) Peta Pola Ruang Kel. Klasmelek

8) Peta Pola Ruang Kel. Wen

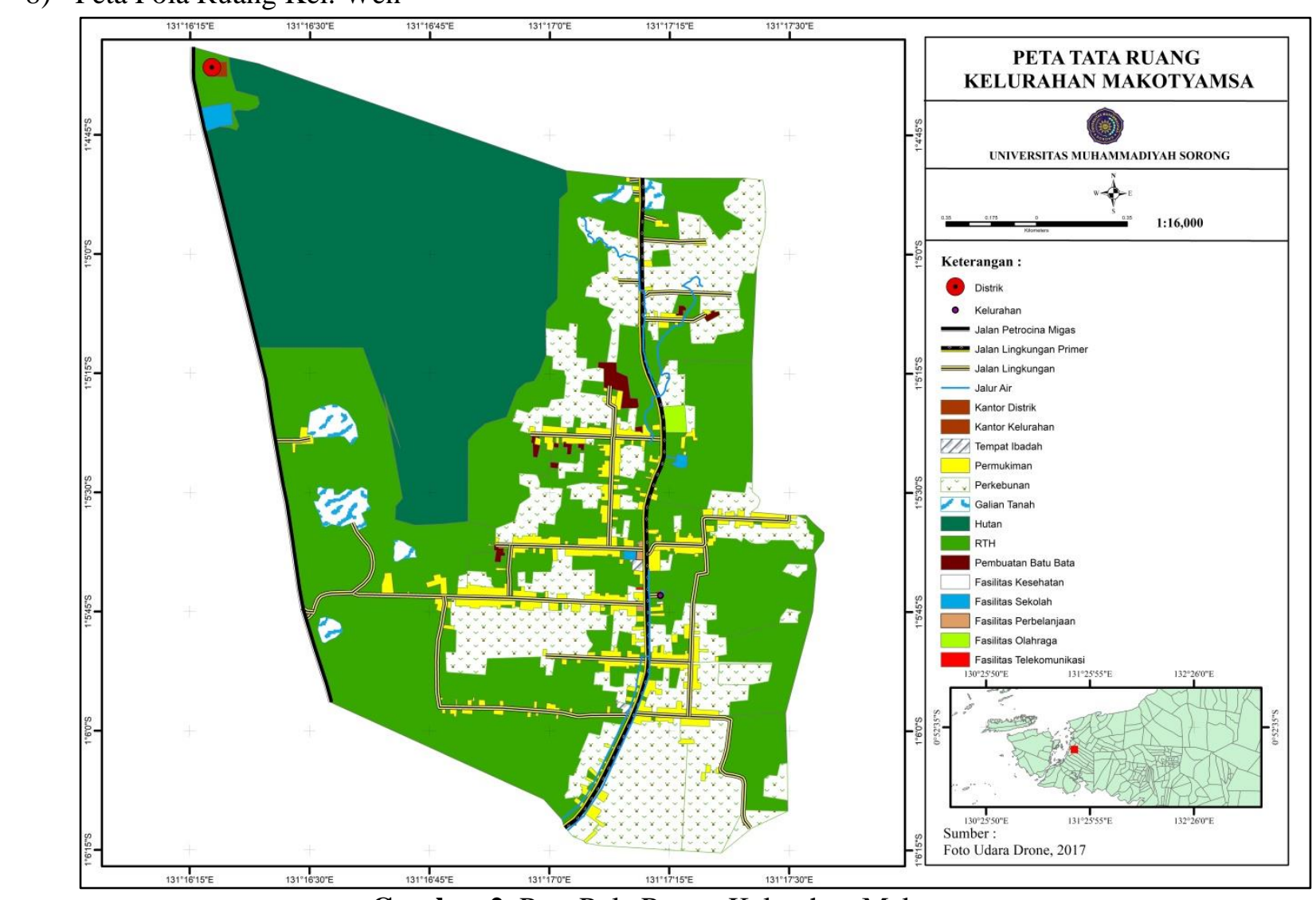

Gambar 2. Peta Pola Ruang Kelurahan Makotyamsa

(Sumber : Hasil Analisis Digitasi ArcGis)
9) Peta Pola Ruang Distrik Mayamuk

10) Peta Administrasi Distrik Mayamuk 


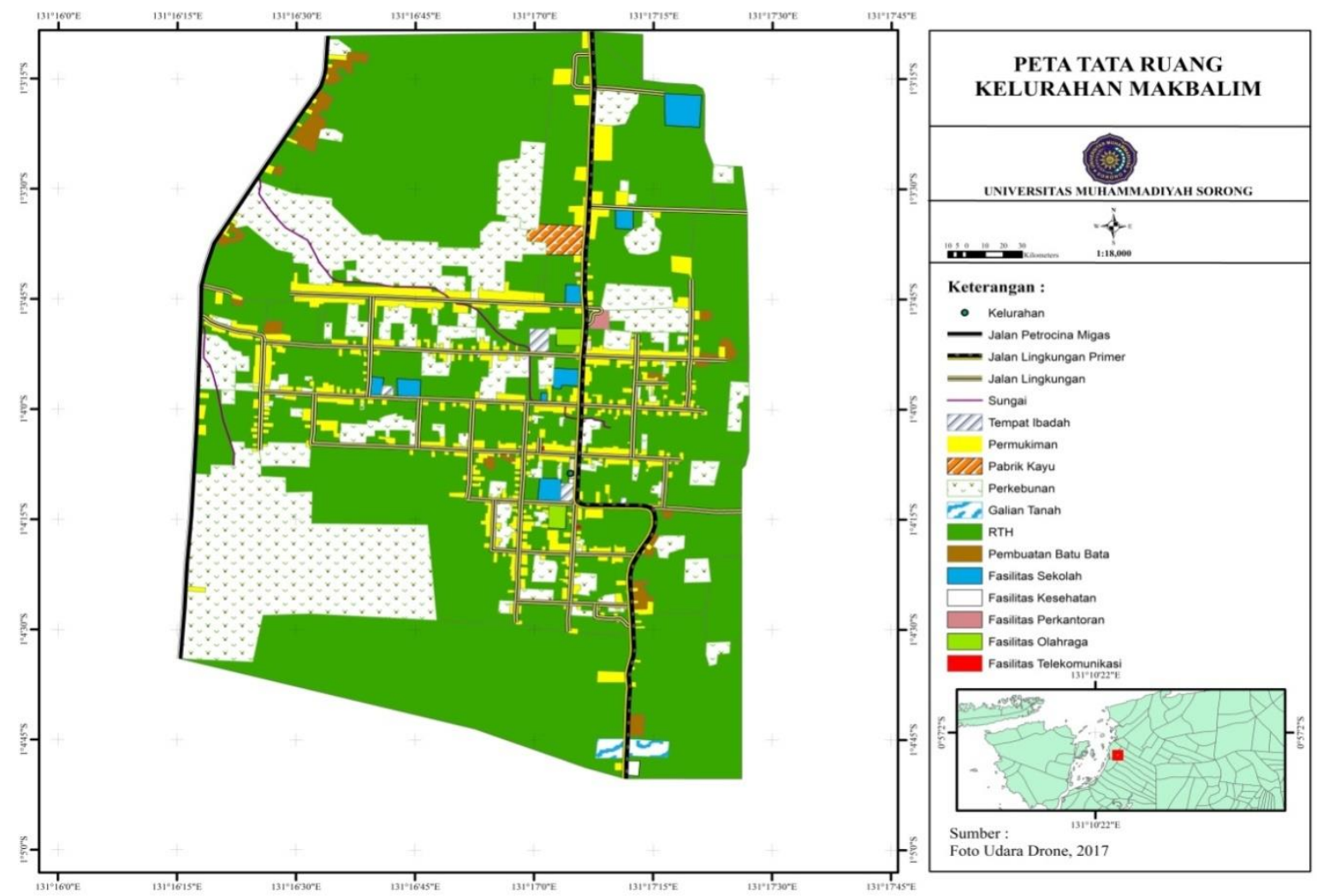

Gambar 3. Peta Pola Ruang Kelurahan Makbalim (Sumber :Hasil Analisis Digitasi ArcGis)
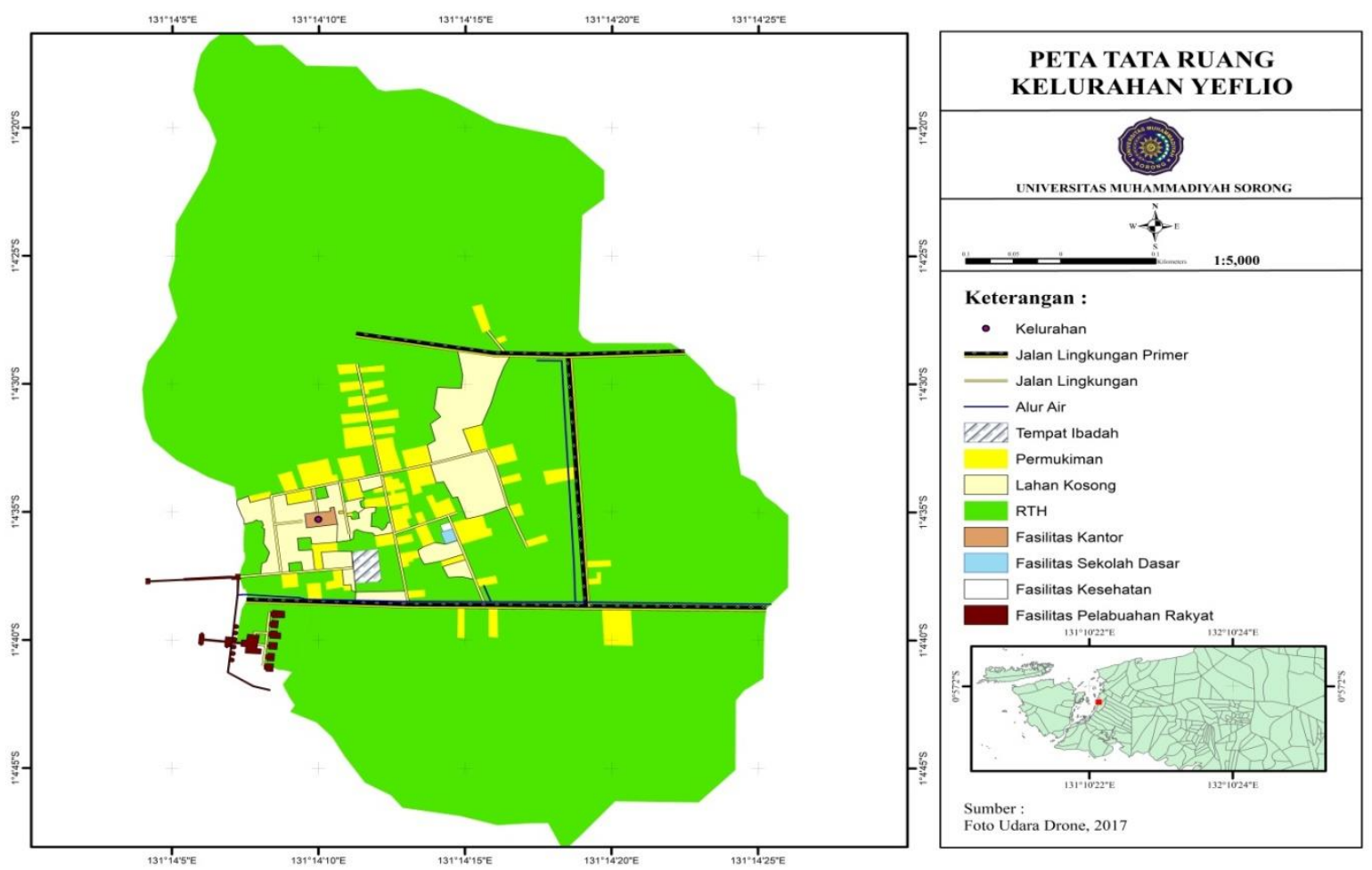

Gambar 4. Peta Pola Ruang Kelurahan Yeflio (Sumber :Hasil Analisis Digitasi ArcGis) 

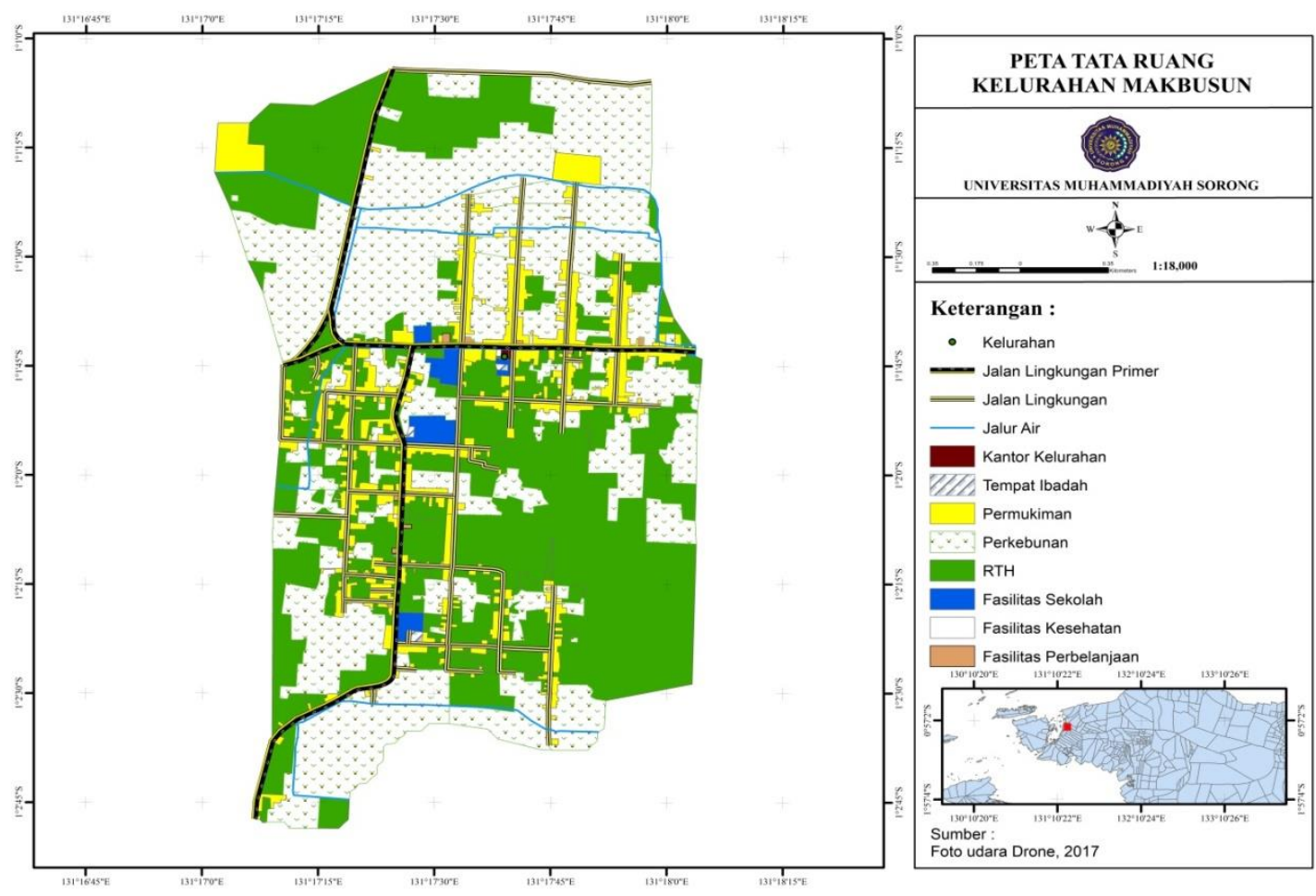

Gambar 5. Peta Pola Ruang Kelurahan Makbusun (Sumber : Hasil Analisis Digitasi ArcGis)
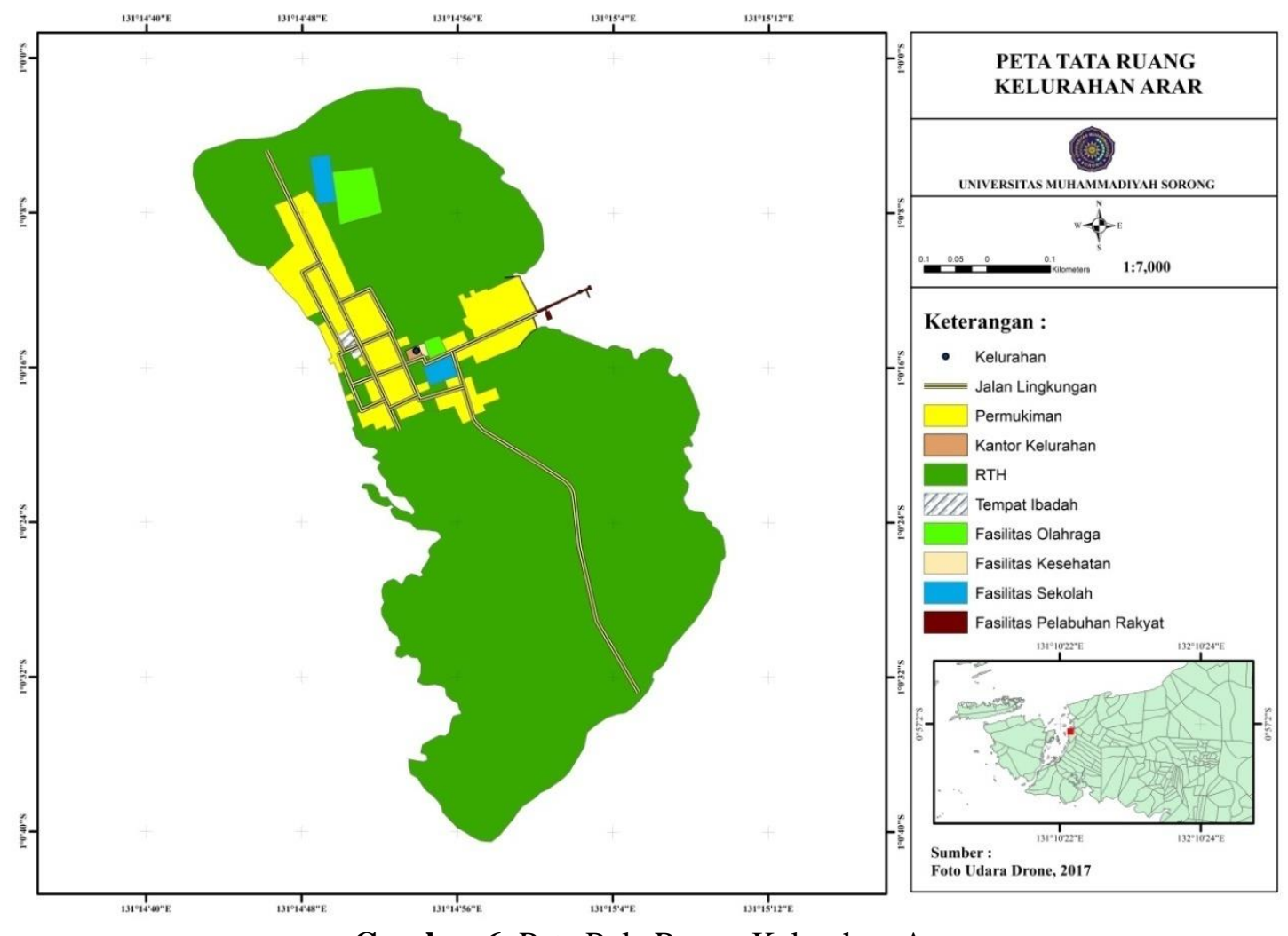

Gambar 6. Peta Pola Ruang Kelurahan Arar

(Sumber :Hasil Analisis Digitasi ArcGis) 


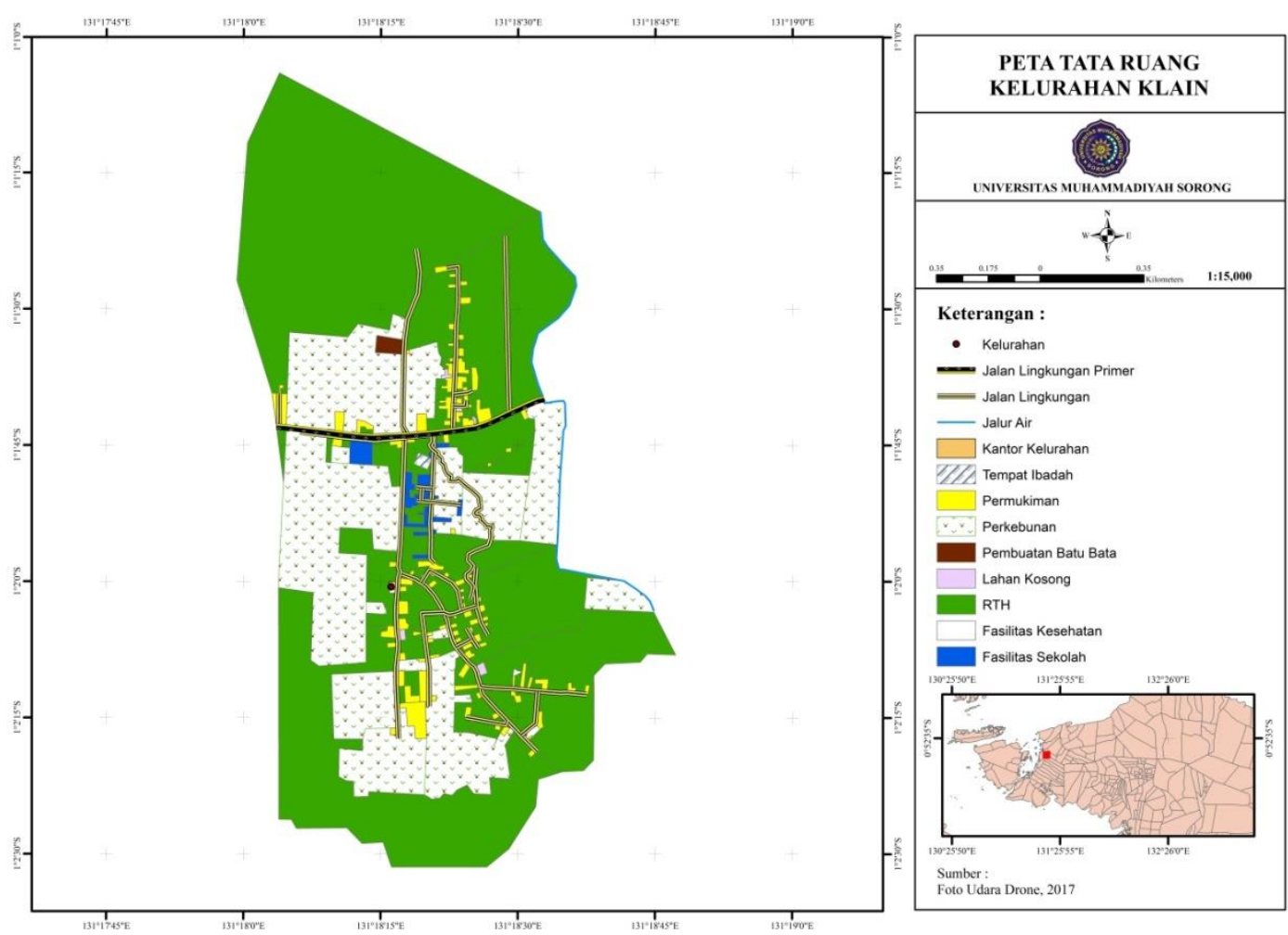

Gambar 7. Peta Pola Ruang Kelurahan Klain (Sumber :Hasil Analisis Digitasi ArcGis)

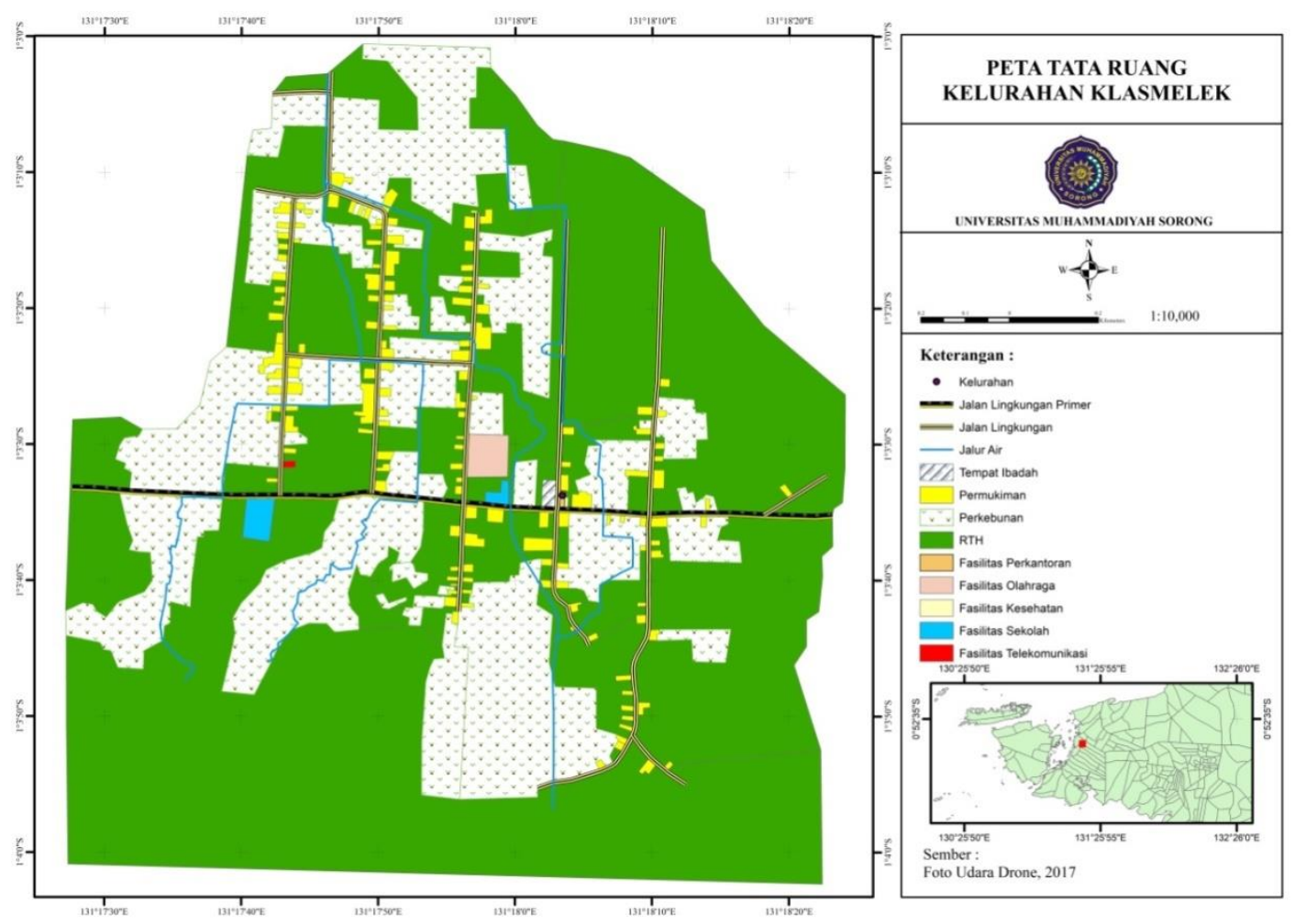

Gambar 8. Peta Pola Ruang Kelurahan Klasmelek (Sumber :Hasil Analisis Digitasi ArcGis) 


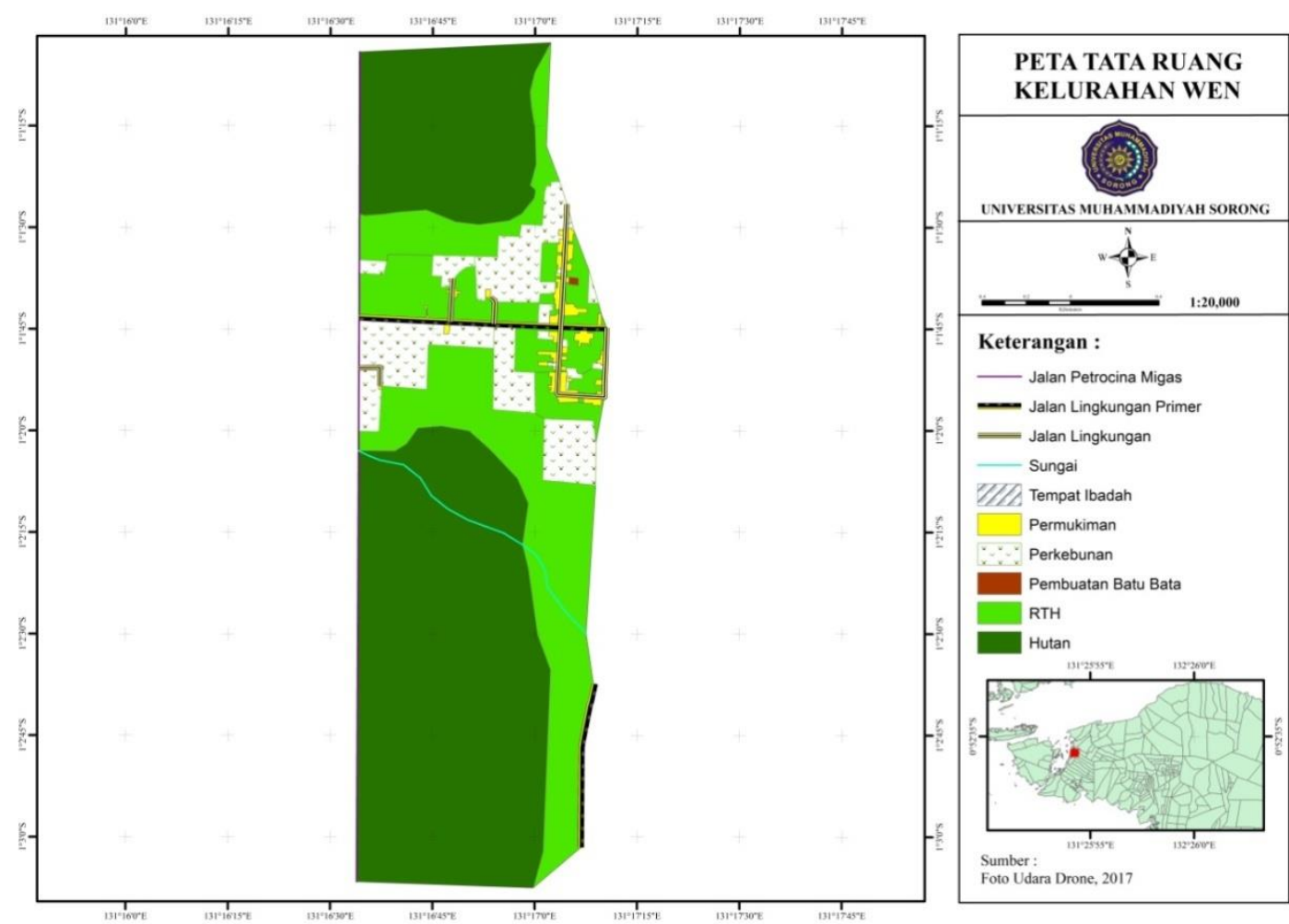

Gambar 9. Peta Pola Ruang Kelurahan Wen

(Sumber :Hasil Analisis Digitasi ArcGis)

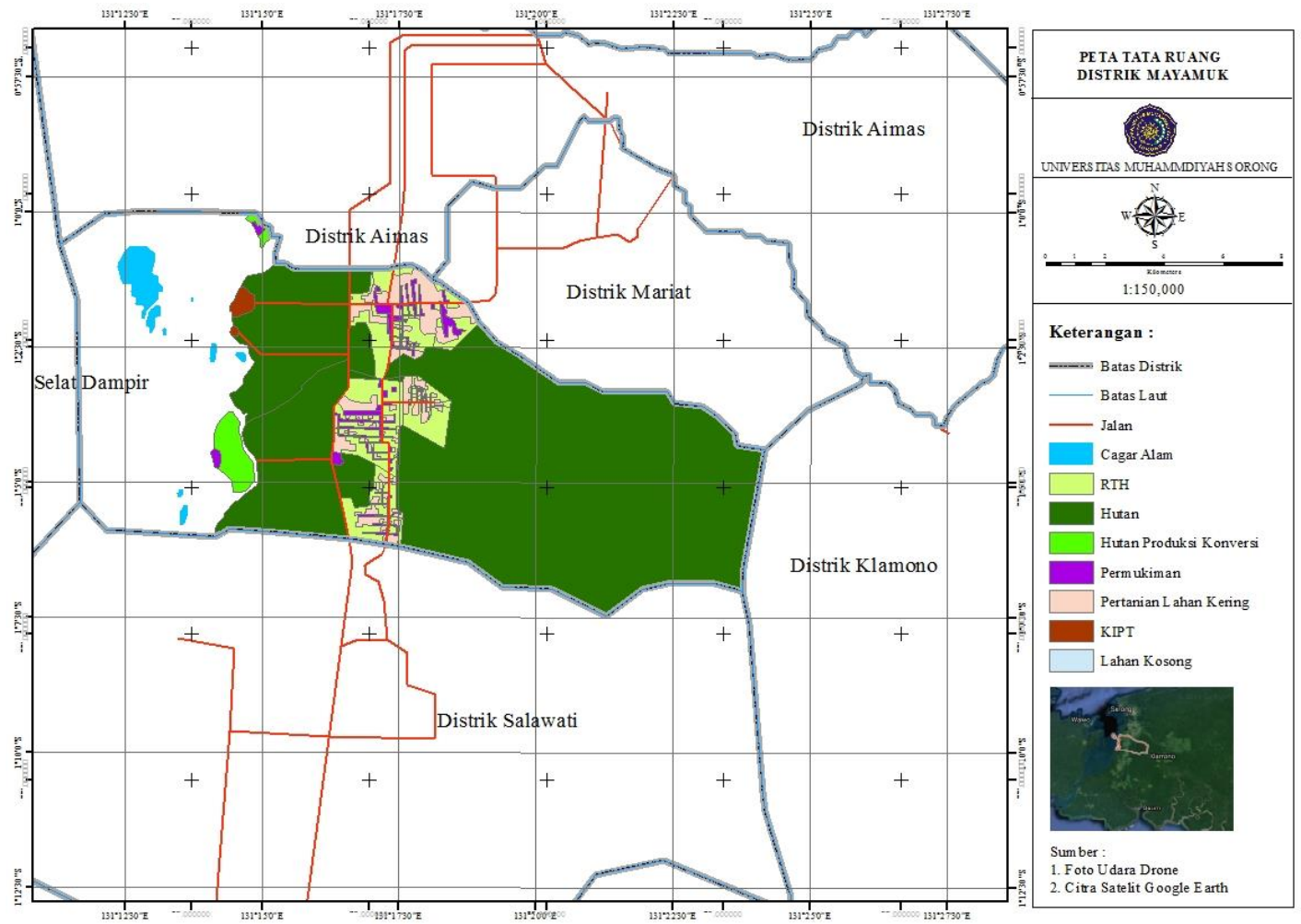

Gambar 10. Peta Pola Ruang Distrik Mayamuk (Sumber :Hasil Analisis Digitasi ArcGis) 


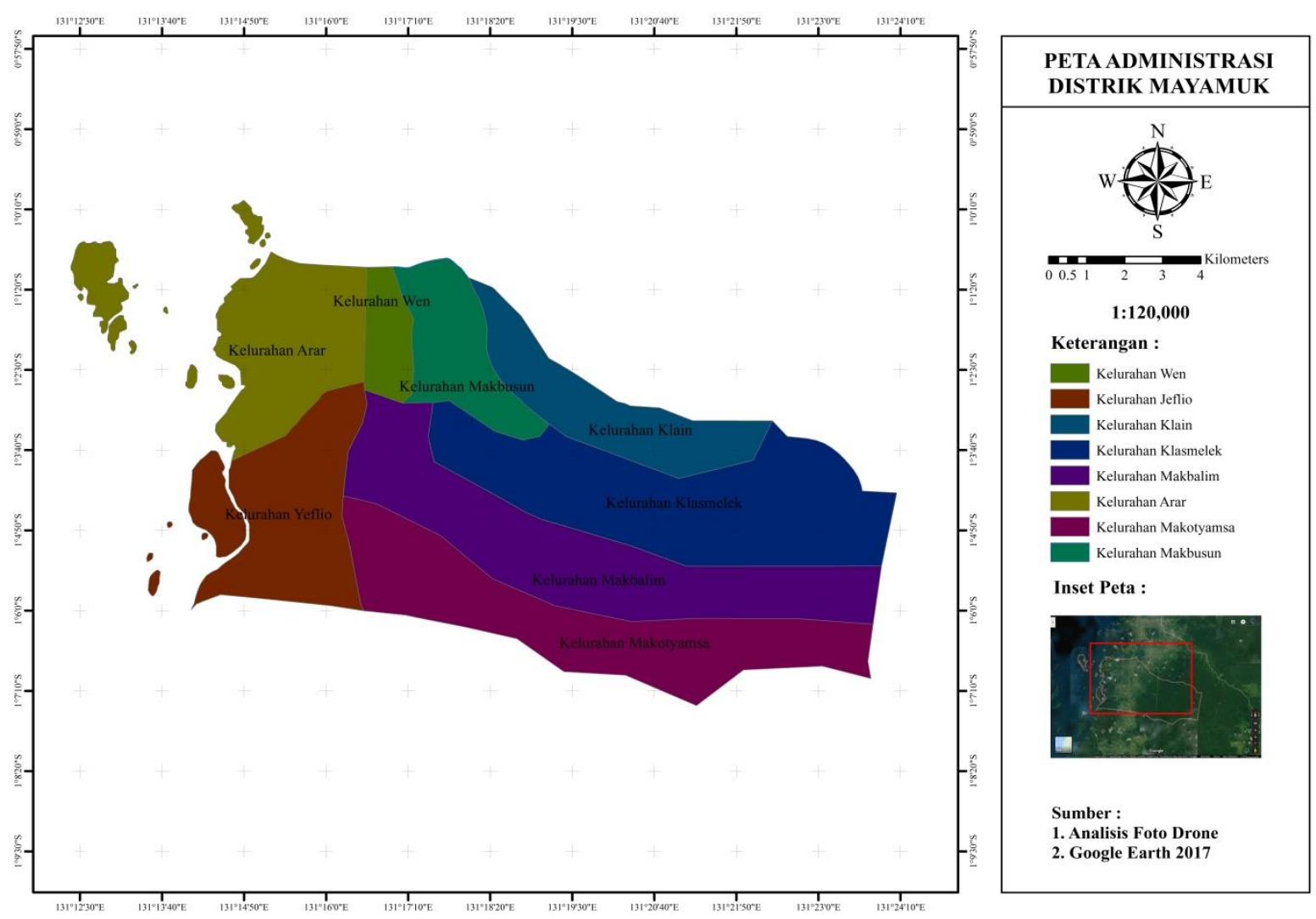

Gambar11. Peta Pola Ruang Distrik Mayamuk

(Sumber : Hasil Analisis Digitasi ArcGis)

\section{Kesimpulan}

Berdasarkan hasil penelitian yang telah dilaksanakan penulis dapat menyimpulkan bahwa :

1. Perbandingan luas Distrik Mayamuk menurut RTRW adalah 14.534,47 Ha sedangkan hasil analisis $14.450,71 \mathrm{Ha}$ dengan selisih $83,76 \mathrm{Ha}$.

2. Kesesuaian penggunaan lahan menurut RTRW dengan hasil analisis sebagai berikut:

a. Untuk kawasan lindung cagar alam yang direncanakan sebesar $4,26 \%$ sedangkan hasil analisis $1,95 \%$ dari luas distrik dengan selisih $2,32 \%$.

b. Untuk kawasan budidaya hutan produksi komersial (HPK) yang direncanakan sebesar 2,34\% sedangkan hasil analisis $92,16 \%$ dari luas distrik dengan selisih $89,82 \%$.

c. Untuk kawasan budidaya permukiman yang direncanakan sebesar $12,01 \%$ sedangkan hasil analisis $1,42 \%$ dari luas distrik dengan selisih $10,59 \%$.

d. Untuk kawasan budidaya pertanian lahan kering yang direncanakan sebesar 46,94\% sedangkan hasil analisis 4,29\% dari luas distrik dengan selisih $42,65 \%$. e. Untuk kawasan lahan kosong dari hasil analisis didapat sebesar $0,02 \%$ dari luas wilayah distrik yang belum dimanfaatkan sesuai peruntukannya.

f. Untuk kawasan budidaya $\mathrm{AL}$ yang direncanakan sebesar 4,06\% sedangkan dari hasil analisis belum terlaksana. Jadi untuk kawasan budidaya AL harus dilaksanakan sesuai dengan rencana pola ruang Distrik Mayamuk.

g. Bentuk existing pada peta rencana tata ruang wilayah (RTRW) Distrik Mayamuk berbeda dengan bentuk existing dilapangan pada hasil produk peta drone.

3. Peta tiap kelurahan Distrik Mayamuk tidak seluruhnya kawasan hutan dapat diambil citra foto udaranya karena kesulitan teknis (terbatasnya spesifikasi jangkauan drone).

\section{Saran}

Untuk memperoleh hasil yang lebih baik dalam melaksanakan penelitian ini, dikemukakan saran sebagai berikut :

1. Sebaiknya menggunakan digitasi luas dari citra satelit atau citra foto drone terbaru karena sesuai dengan kondisi lapangan sekarang. 
2. Perlu adanya pengawasan pola ruang agar dapat terlaksana sesuai dengan peruntukannya.

\section{Daftar pustaka}

Balai Diklat 12 PUPR, "Pengukuran dan Pemetaan Digital Dalam GIS”, Ir. Made Bagus Budihardjo, MA (2016).

Diktat Aplikasi GPS dalam Bidang Pekerjaan Umum, "Sistem Informasi Geografis dan Analisis Geospasial”, Komang Sri Hartini (2016). 